\title{
Forskolin Enhances Inward Rectifier Current in Neurons of Rat Suprachiasmatic Nucleus
}

\author{
TAKASHI AKASU*, SHINGO SHOJI ${ }^{\dagger}$ AND MASARU ISHIMATSU*† \\ *Department of Physiology and ${ }^{\dagger}$ Department of Endocrinology and Metabolism, \\ Kurume University School of Medicine, Kurume, 830 Japan
}

Received for publication July 28, 1992

\begin{abstract}
Key words: suprachiasmatic nuclei $-\mathrm{I}_{\mathrm{H}}-$ voltage-clamp - forskolin cyclic AMP
\end{abstract}

In central neurons, a potential role of inward rectifier current, $\mathrm{I}_{\mathrm{H}}$, carried by both sodium and potassium ions has been suggested to contribute to rhythmic cellular oscillations (Griffith, 1988; Alonso and Llinás, 1989; McCormick ane Pape, 1990). Recent voltage-clamp studies using whole-cell recording techniques have reported that the activation of $I_{H}$ can be regulated by basal activity of adenylate cyclase, presumably through a cyclic adenosine monophosphate (AMP)-dependent kinase in vertebrate nerve cells (McCormick and Pape, 1990; Tokimasa and Akasu, 1990). The suprachiasmatic nucleus $(\mathrm{SCN})$ of the ventral hypothalamus of mammals is strongly implicated as an intrinsic pacemaker component in regulation of circadian rhythmicity (Rusak and Zucker, 1979; Takahashi and Zatz, 1982; Turek, 1985; Meijer and Rietveld, 1989; Thomson and West, 1990). In the present study, we have made voltageclamp recordings from neurons of the SCN using a rat brain slice preparation, in vitro, to investigate the role of intracellular cyclic AMP in regulating $\mathrm{I}_{\mathrm{H}}$.

Male Wistar-Kyoto rats weighing 200$300 \mathrm{~g}$ were maintained in a temperature- controlled room $\left(22-25{ }^{\circ} \mathrm{C}\right)$ and exposed to $14: 10 \mathrm{~h}$ light-dark cycle (light on at 07.00 ) for more than 2 weeks. The rats were sacrificed by decapitation in the morning (after 09.00) of the day. Their brains were removed rapidly and slices $(500 \mu \mathrm{m}$ in thickness) containing the entire SCN were cut with a Vibroslice (Campden Instruments USA). Slices were submerged in a recording chamber and superfused at $32-34{ }^{\circ} \mathrm{C}$ with ASCF $(\mathrm{pH} 7.4)$ of the following composition (mM): $\mathrm{NaCl} 117$, $\mathrm{KCl} 4.7, \mathrm{CaCl}_{2} 2.5, \mathrm{MgCl}_{2} 1.2, \mathrm{NaHCO}_{3}$ 25, $\mathrm{NaH}_{2} \mathrm{PO}_{4} 1.2$ and Glucose 11. To record inward rectifier currents, SCN neurons were superfused with a Krebs solution containing nominally zero calcium, TTX $(1 \mu \mathrm{M})$, TEA $(30 \mathrm{mM}), 4$-AP $(1 \mathrm{mM})$ and cadmium $(500 \mu \mathrm{M})$.

Glass micropipettes were filled with $4 \mathrm{M}$ potassium citrate $(100-140 \mathrm{M} \Omega)$. Recordings of the membrane potential and current from SCN neurons were amplified with an Axoclamp 2A amplifier (Axon Instruments). pClamp software program (Axon Instruments) operating on an IBM AX computer (Sanyo) was used to analyze membrane currents. Data are expressed as mean $\pm \mathrm{SE}$.

Reprint requests to: Dr. Takashi Akasu, Department of Physiology, Kurume University School of Medicine, 67 Asahi-machi, Kurume, 830 Japan 
Under single-electrode voltage-clamp, hyperpolarizing steps from a holding potential of $-60 \mathrm{mV}$ resulted in a slow inward relaxation in SCN neurons (Fig. 1). Instantaneous currents obtained at the end of the hyperpolarizing step command were always greater than those measured at the beginning of the step, indicating that it represented the activation of an inward current, rather than de-activation of an outward current. The amplitude of $\mathrm{I}_{\mathrm{H}}$ increased with increase in the size of hyperpolarizing voltage steps. The current did not decay during a voltage step longer than $2 \mathrm{~s}$ in duration, indicating little inactivation of the conductance underlying $\mathrm{I}_{\mathrm{H}}$. Bath-application of cesium $(1-2 \mathrm{mM})$ strongly reduced $\mathrm{I}_{\mathrm{H}} \quad(\mathrm{n}=8)$ (Fig. 1A).

Forskolin (1-10 $\mu \mathrm{M})$ applied to the superfusing solution increased the amplitude of $\mathrm{I}_{\mathrm{H}}$ produced by a step command from -60 to $-90 \mathrm{mV}$ by $36 \pm 5 \% \quad(n=4)$ (Fig. 1B). The effect of forskolin appeared within $2 \mathrm{~min}$, when the forskolincontaining solution reached the recording chamber, and disappeared within $20 \mathrm{~min}$ after switching to the recovery solution. The amplitude of $\mathrm{I}_{\mathrm{H}}$ was also enhanced by the membrane-permeable cyclic AMP analogue, 8-bromo-cyclic AMP. A forskolin analogue, 1,9-dideoxy-forskolin which only weakly stimulates adenylate cyclase, caused no significant facilitation of $\mathrm{I}_{\mathrm{H}}$. Over the whole voltage range tested, $I_{H}$ was well fitted by a singleexponential function. The rate of activation of $I_{H}$ increased as the neuron was hyperpolarized (Fig. 2A). Activation time constants were $1-2 \mathrm{~s}$ at $-70 \mathrm{mV}$ and 250 $\mathrm{ms}$ at $-95 \mathrm{mV}$. Forskolin did not change the activation and deactivation time constants (Fig. 2).
A
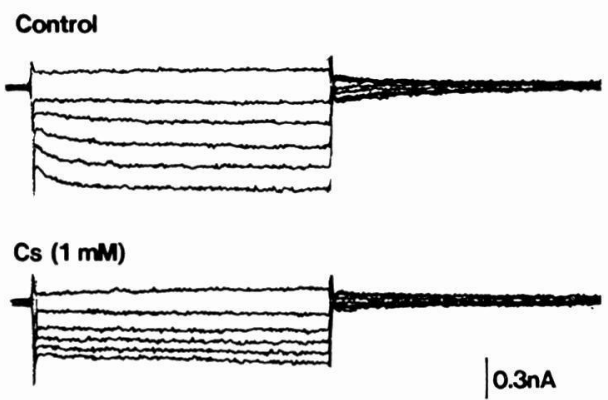

Vh. $-60 \mathrm{mV}$
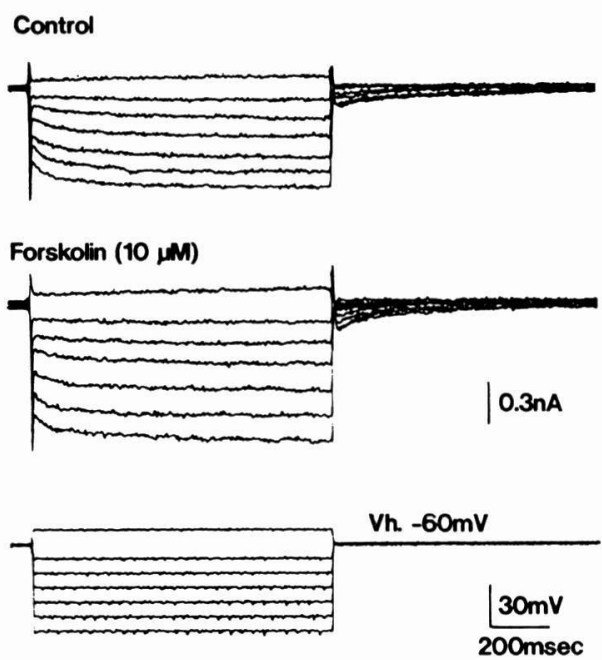

Fig. 1. Effect of cesium (A) and forskolin (B) on $\mathrm{I}_{\mathrm{H}}$ recorded from two different neurons. Cesium $(1 \mathrm{mM})$ and forskolin $(10 \mu \mathrm{M})$ were added to the superfusing solution for $5 \mathrm{~min}$. The neurons were initially held at $-60 \mathrm{mV}$ and subjected to hyperpolarizing voltage steps from -70 to $-110 \mathrm{mV}(\mathrm{A})$ and $-120 \mathrm{~m} \mathrm{~V}$ (B). Note that $\mathrm{I}_{\mathrm{H}}$ is depressed by cesium, while it is enhanced by forskolin. 

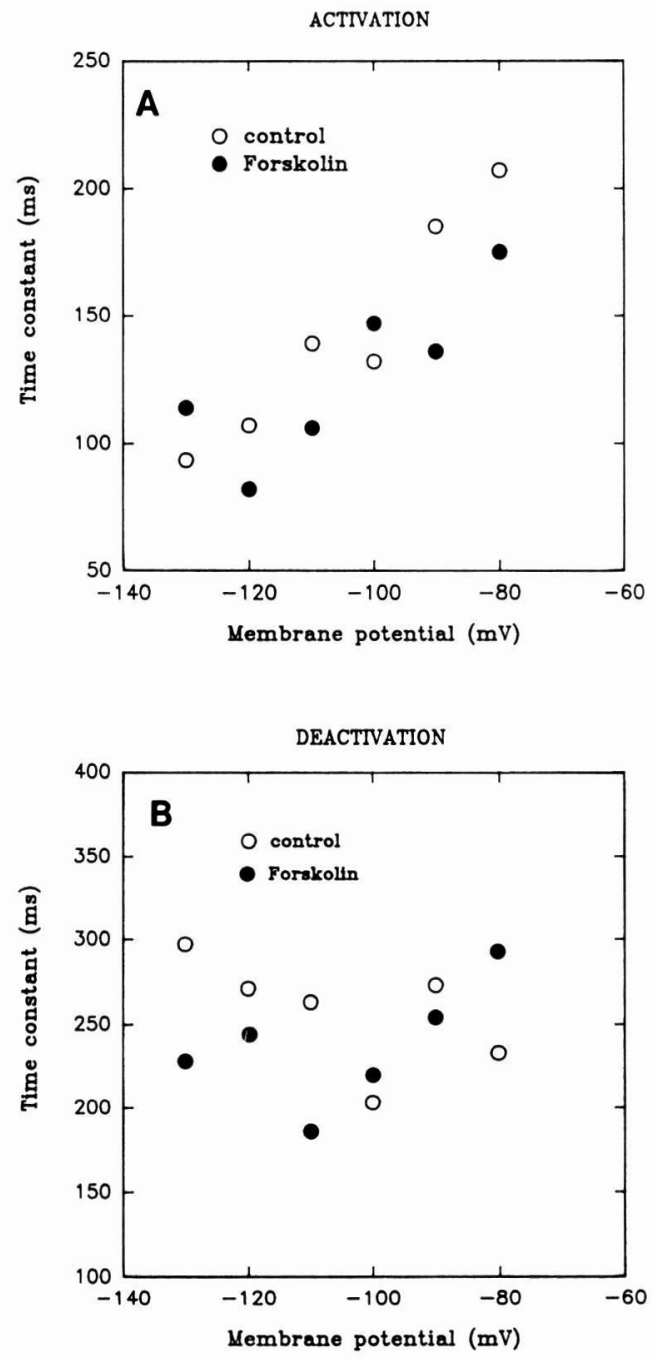

Fig. 2. Effect of forskolin $(10 \mu \mathrm{M})$ on the time constants for activation (A) and deactivation (B) of $\mathrm{I}_{\mathrm{H}}$. The activation time constants were taken at potentials between -80 and $-130 \mathrm{mV}$. The deactivation time constants were obtained at a holding potential of $-50 \mathrm{mV}$. In graph $\mathrm{B}$, abscissa indicates holding membrane potentials to activate $I_{H}$.

The activation curve of the membrane conductance underlying $\mathrm{I}_{\mathrm{H}}\left(\mathrm{G}_{\mathrm{H}}\right)$ was constructed by measuring tail currents elicited by repolarizing the membrane to
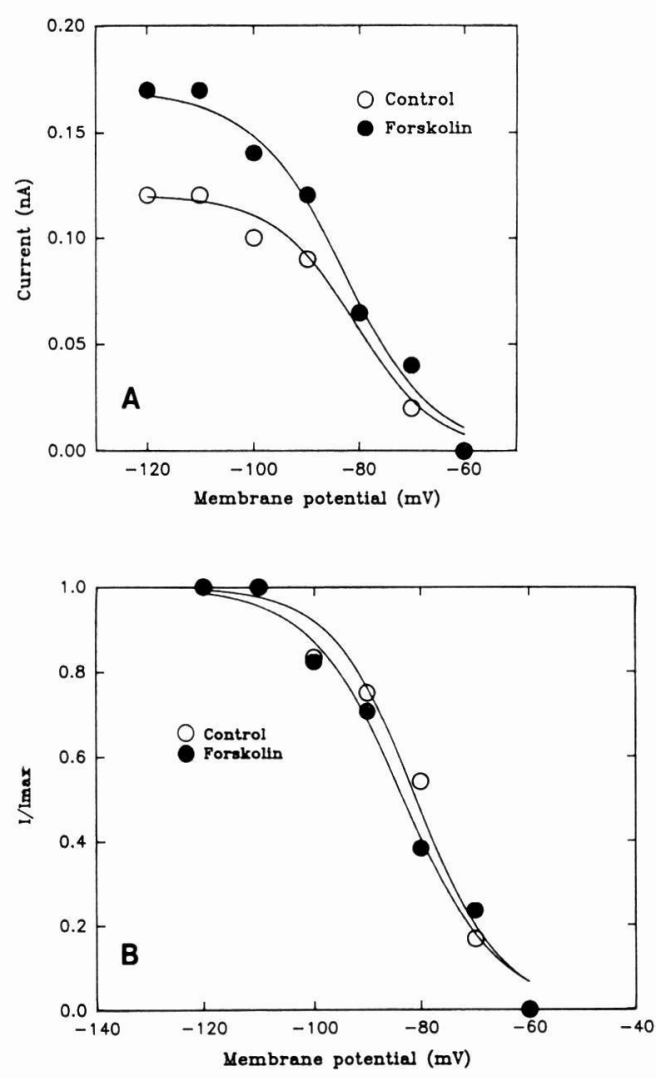

Fig. 3. Effect of forskolin $(10 \mu \mathrm{M})$ on activation curves for $\mathrm{G}_{\mathrm{H}}$ obtained the tail currents of $\mathrm{I}_{\mathrm{H}}$. The initial holding potential was $-50 \mathrm{mV}$. In graph $\mathrm{B}$, ordinate indicates normalized amplitude of $\mathrm{I}_{\mathrm{H}}$ tail current recorded at potentials between -60 and $-120 \mathrm{mV}$. The tail current obtained at $-120 \mathrm{mV}$ represents as the maximum amplitude $\left(I_{\max }\right)$. Note that forskolin increases the amplitude of $I_{H}$ but it does not change the activation voltage range and the half-activation voltage.

holding potential of $-50 \mathrm{mV}$ following voltage steps between -60 and $-120 \mathrm{mV}$. The resulting data were well fit by the Boltzman equation (Mayer and Westbrook, 1983; Tokimasa and Akasu, 1990). Activation of $\mathrm{G}_{\mathrm{H}}$ appeared at approximately $-65 \mathrm{mV}$ and reached its maximum at -120 $\mathrm{mV}$. At $-95 \mathrm{mV}$, the amplitude of $\mathrm{I}_{\mathrm{H}}$ 
ranged from 0.1 to $0.2 \mathrm{nA}$ (Fig. $3 \mathrm{~A}$ ). Forskolin $(10 \mu \mathrm{M})$ enhanced the amplitude of the tail current at all holding membrane potentials (Fig. 3A). The tail current amplitudes were normalized to maximal amplitude and plotted against the membrane potential to which the neurons were stepped during activation of $\mathrm{I}_{\mathrm{H}}$. The half-activation of $\mathrm{G}_{\mathrm{H}}$ occurred at a holding potential of $-84 \mathrm{mV}$ with a slope of 7.9 (Fig. 3B). Forskolin altered neither activation and inactivation time courses of $\mathrm{I}_{\mathrm{H}}$ nor the activation curve of $\mathrm{G}_{\mathrm{H}}$.

Voltage-clamp study clearly showed that hyperpolarizing step commands evoked a current relaxation, associated with time- and voltage-dependent increase in membrane conductance in SCN neurons. The result that cesium (1-2 mM) strongly reduced the hyperpolarizationactivated (inward rectifier) current suggests that it is a type of the $\mathrm{I}_{\mathrm{H}}$, a nonselective cation current (Halliwell and Adams, 1982; Mayer and Westbrook, 1983; Spain et al. 1987). Forskolin and 8-bromocyclic AMP enhanced the amplitude of $\mathrm{I}_{\mathrm{H}}$ without changing the time courses of $\mathrm{I}_{\mathrm{H}}$ activation and deactivation. These agents did not change the activation voltage of $\mathrm{G}_{\mathrm{H}}$. Furthermore, 1,9-dideoxyforskolin had no significant effect on $\mathrm{I}_{\mathrm{H}}$. These results suggest that an increased intracellular cyclic AMP enhances $\mathrm{I}_{\mathrm{H}}$ probably by an increase in the number of channels available.

A majority of neurons in the SCN displayed no event comparable to the late, long-lasting calcium-dependent afterhyperpolarization (AHP) of the action potential but only the fast AHP (Akasu, personal communication), similar to other spontaneous fast-spiking neurons of the CNS (Ashwood et al. 1984; McCormick et al. 1985; Griffith, 1988; Thomson and West, 1990). The inward rectification could contribute to the firing pattern of central neurons, acting as a pacemaker current (Halliwell and Adams, 1982; Mayer and Westbrook, 1983). Griffith (1988) has also suggested that the $\mathrm{I}_{\mathrm{H}}$ may contribute to the fast spike AHP in spontaneously firing neurons of guinea-pig forebrain nuclei. It is possible that the basal activity of adenylate cyclase of neurons can control the neuronal pacemaker activity by modulating the rate of firing of action potentials in the rat SCN.

Acknowledgments: This work was supported by a Grant-in-Aid for Scientific Research from the Ministry of Education, Science and Culture of Japan.

\section{References}

Alonso, A. and Llinás, R.R. (1989). Subthreshold $\mathrm{Na}^{+}$-dependent theta-like rhythmicity in stellate cells of entorhinal cortex layer II. Nature 342, 175-177.

Ashwood, T.J., Lancaster, B. and Wheal, H. V. (1984). In vivo and in vitro studies on putative interneurones in the rat hippocampus: possible mediators of feed-forward inhibition. Brain Res. 293, 279-291.

Griffith, W.H. (1988). Membrane properties of cell types within guinea pig basal forebrain nuclei in vitro. J. Neurophysiol. 59, 1590-1612.

Halliwell, J. V. and Adams,P.R. (1982). Voltage-clamp analysis of muscarinic excitation in hippocampal neurons. Brain Res. 250, 7192.

Mayer, M.L. and Westbrook, G.L. (1983). A voltage-clamp analysis of inward (anomalous) rectification in mouse spinal sensory ganglion neurones. J. Physiol. (Lond.) 340, 19-45.

McCormick, D. A., Connors, B. W., Lighthall, J. W. and Prince, D. A. (1985). Comparative electrophysiology of pyramidal and sparsely spiny stellate neurons of the neocortex. J. Neurophysiol. 54, 782-806.

McCormick, D. A. and Pape,H. -C. (1990). Properties of a hyperpolarization-activated cation current and its role in rhythmic oscillation in thalamic relay neurones. J. Physiol. (Lond.) 431, 291-318.

Meijer, J.H. and Rietveld, W. J. (1989). Neuro- 
physiology of the suprachiasmatic circadian pacemaker in rodents. Physiol. Rev. 69, 671707.

Rusak,B. and Zucker, I. (1979). Neural regulation of circadian rhythms. Physiol. Rev. 59, 449-526.

Spain, W. J., Schwindt, P.C. and Crill, W.E. (1987). Anomalous rectification in neurons from cat sensorimotor cortex in vitro. $\mathrm{J}$. Neurophysiol. 57, 1555-1576.

TAKAHASHI, J.S. and ZATZ,M. (1982). Regulation of circadian rhythmicity. Science 217, 1104-
1111.

Thomson, A.M. and West,D.C. (1990). Factors affecting slow regular firing in the suprachiasmatic nucleus in vitro. J. Biol. Rhythms $5,59-75$.

Tokimasa, T. and Akasu, T. (1990). Cyclic AMP regulates an inward rectifying sodium-potassium current in dissociated bull-frog sympathetic neurones. J. Physiol. (Lond.) 420, 409-429.

Turek, F.W. (1985). Circadian neural rhythms in mammals. Annu. Rev. Physiol. 47, 49-64. 